\title{
As vozes daqueles envolvidos na inclusão de aprendizes autistas nas aulas de Matemática
}

\section{The voices of those involved in the inclusion of autistic learners in Mathematics classes}

\section{Roberta Caetano Fleira'}

Solange Hassan Ahmad Ali Fernandes²

${ }^{1}$ Universidade Anhanguera (UNIAN), São Paulo, SP, Brasil. Autora Correspondente: robertafleira@hotmail.com

${ }^{2}$ Universidade Ibirapuera (UNIB), São Paulo, SP, Brasil.

Resumo: Por meio deste artigo busca-se compreender o sentido que quatro professoras da Educação Básica, que atuam com aprendizes pertencentes ao público-alvo da Educação Especial com Transtorno do Espectro Autista (TEA), atribuem ao termo inclusão e analisar as práticas pedagógicas em suas aulas de Matemática. A metodologia adotada foi o estudo de caso e a coleta de dados foi realizada por meio de entrevistas estruturadas, gravadas em áudio. Neste estudo, a concepção de inclusão aparece de duas formas: como processo e como produto. A proposta consistiu em, a partir das transcrições das entrevistas e por meio da análise de discurso, analisar as crenças epistemológicas e as ações pedagógicas desencadeadas pelas professoras em suas salas de aula para a inclusão de alunos com TEA. Os resultados permitiram perceber que, mesmo em diferentes níveis, todas têm expectativas a respeito da aprendizagem dos seus alunos e acreditam no potencial deles, indiferentemente da especificidade de cada um.

Palavras-chave: Ensino de matemática; Educação básica; Estudante especial; Educação inclusiva; Aluno autista.

Abstract: With this article, we seek to comprehend how four Elementary School teachers who work with Autism Spectrum Disorder (ASD) learners construe the term inclusion, and to analyse teaching practices in their mathematics lessons. The methodology was case study, and data collection was carried out through structured interviews that were audiorecorded. In this study, the concept of inclusion appears as both process and product. Our proposal has been based on the transcription of the interviews and discourse analysis to investigate the epistemological convictions and the teaching actions initiated by the teachers in their classrooms with ASD students. The results enabled us to conclude that even if on different levels, all of the teachers have expectations related to the learning of their students and believe in their potential, irrespective of the particular characteristics of individual learners. students.

Keywords: Mathematics teaching; Basic education; Inclusive education; Autistic 


\section{Introdução}

Inclusão em educação pode ser vista, dessa forma, como um processo de transformação de valores em ação, resultando em práticas e serviços educacionais, em sistemas e estruturas que incorporam tais valores. Podemos especificar alguns deles, porque são parte integral de nossa concepção de inclusão; outros podemos identificar com um razoável grau de certeza, com base no que aprendemos a partir de experiências. Isto significa que a inclusão só poderá ser totalmente compreendida quando seus valores fundamentais forem exaustivamente clarificados em contextos particulares (AINSCOW, 2009, p. 21).

A inclusão escolar é uma das dimensões da inclusão social que só é alcançada se garantida por meio da promoção da acessibilidade à educação com qualidade, bem como aos outros direitos fundamentais (BASTOS, 2019). Ensinar, porém, não se resume em dar acesso, requer também a promoção de oportunidades para que o aprendiz possa fazer uso dos conhecimentos constituídos em sua vida. Isso nos leva a outro desafio crítico - preparar os professores para trabalhar com todos os alunos, incluindo aqueles que estavam em escolas especializadas ou se encontravam excluídos do ambiente escolar, um processo que requer a ressignificação de suas crenças pedagógicas e epistemológicas. A Educação Especial na perspectiva inclusiva, no Brasil, vem se construindo historicamente, acompanhando os processos legais e os apelos sociais. No entanto, apesar de sua especificidade, ela não tem se organizado com e para seus atores (FERNANDES, 2017).

Neste artigo, nosso olhar está voltado às crenças epistemológicas e às práticas pedagógicas de professoras que atuam na Educação Especial, em particular com a inclusão de educandos com autismo, público este que apresenta características e singularidades de natureza sensório-perceptiva, emocional, socioafetiva e, algumas vezes, têm associadas dificuldades comportamentais e de aprendizagem no cotidiano escolar. Diante desse contexto, é essencial que os profissionais envolvidos disponham de atenção e ações voltadas para atender às necessidades específicas desses educandos no ambiente escolar, juntamente com seus pares.

As pessoas com Transtorno do Espectro Autista (TEA) apresentam características comportamentais peculiares desde o início da infância. O uso do termo Espectro é devido à grande variedade de manifestações do transtorno, que dependem da condição de cada autista, do nível de desenvolvimento e da idade cronológica. O TEA engloba transtornos antes chamados de autismo infantil precoce, autismo infantil, autismo de Kanner, autismo de alto funcionamento, autismo atípico, transtorno global do desenvolvimento sem outra especificação, transtorno desintegrativo da infância e transtorno de Asperger (AMERICAN PSYCHIATRIC ASSOCIATION, 2014, p. 50).

Bosa e Camargo (2009) destacam que o contexto escolar oferece a oportunidade de estabelecer contatos sociais, favorecendo o desenvolvimento da criança autista, assim como o das demais crianças, na medida em que elas convivem e aprendem com as diferenças. Nessa circunstância, o professor tem papel fundamental, mediando as interações que favorecem o desenvolvimento de diferentes habilidades cognitivas e socioemocionais. O nosso propósito com este artigo é dar voz às professoras que participam do cotidiano escolar com aprendizes autistas, compreender o sentido que elas atribuem ao termo inclusão e analisar as práticas pedagógicas empregadas em suas aulas de Matemática. 
Pesquisas neurocientíficas mostram que existem mecanismos neurais mediadores entre as experiências pessoais (relacionadas ao corpo) e o conhecimento, que nos permitem entender as ações executadas pelos outros e decodificar diretamente as emoções e sensações que eles experimentam (COSENZA; GUERRA, 2011; DAMÁSIO, 2005; GALLESE, 2005). Nessa perspectiva, acreditamos que os discursos oriundos das entrevistadas podem destacar aspectos importantes e fundamentais a respeito da inclusão de aprendizes com TEA.

Alguns mitos apresentados nos estudos de Goldberg, Pinheiro e Bosa (2005 apud BOSA; CAMARGO, 2009, p. 69) podem ser desmistificados nas vozes dessas professoras; entre eles destaca-se que, frente à possibilidade de inclusão de um aluno autista em sua classe, o professor demonstra preocupações associadas ao seu receio de lidar com o comportamento atípico que ele acredita ser próprio de um aluno com TEA. De modo geral, a ansiedade do professor está ligada às suas dificuldades de lidar com o 'diferente'.

\section{O estudo e sua perspectiva metodológica}

A metodologia adotada para esta pesquisa é o estudo de caso. De acordo com Ludke e André (1986, p. 17), "[...] o estudo de caso é o estudo de um caso, seja ele simples, específico. O caso é sempre bem delimitado, devendo ter seus contornos claramente definidos no desenrolar do estudo". Nesse caso, nossa proposta é compreender, por meio das falas de professoras que vivenciam a inclusão de alunos com TEA, o sentido/ significado que elas atribuem ao termo inclusão e analisar as implicações desses atributos em suas crenças epistemológicas e as ações pedagógicas desencadeadas em suas salas de aula para fazer a inclusão. Cabe destacar que, neste texto, assumimos a concepção de Vygotsky (2009, p. 465), segundo a qual:

[...] o sentido de uma palavra é a soma de todos os fatos psicológicos que ela desperta em nossa consciência. Assim, o sentido é sempre uma formação dinâmica, fluida, complexa, que tem zonas de estabilidade variadas. O significado é uma das zonas do sentido que a palavra adquire no contexto de um discurso, é uma zona mais estável, uniforme e exata.

Para tanto, realizamos a coleta de dados por meio de entrevistas estruturadas gravadas em áudio, com quatro professoras que atuam com alunos com TEA no ambiente escolar. De acordo com Gil (1999), a entrevista estruturada ocorre com o emprego de uma sequência fixa de perguntas a ser aplicada para todos os entrevistados. Desse modo, espera-se "[...] que o entrevistador não influencie ou interprete as respostas, apenas as reproduza e que não improvise" (GIL, 1999, p. 121). Neste estudo, as questões foram entregues a cada uma das entrevistadas que gravaram suas respostas individualmente. Nosso propósito foi deixá-las o mais à vontade possível, garantindo-Ihes liberdade para as respostas. Todas as entrevistas foram transcritas integralmente para posterior análise.

A escolha das professoras entrevistadas se deu pelo seguinte critério: serem professoras que trabalham nas aulas conteúdos matemáticos com alunos autistas matriculados na Educação Básica. Optamos por utilizar nomes fictícios para as professoras - Renata, Marisa, Sofia e Talita -, que atuam no Ensino Fundamental I de uma instituição particular de ensino, que possui o lema de promover Educação de Qualidade para Todos. A instituição, localizada na cidade de São Paulo, oferece um ambiente inclusivo que possibilita o desenvolvimento das diferentes potencialidades 
do ser humano. A escola possui salas de educação especial e regular. Em alguns casos, dependendo do comprometimento ou da limitação do aluno, há a necessidade de alocá-lo em salas especiais, tratando-se de um procedimento de exceção. A perspectiva consiste em trabalhar com a ideia de que existem múltiplas inteligências, cabendo à escola proporcionar contextos funcionais que as desenvolvam para que, a partir da valorização de suas competências, o aluno melhore a sua autoestima, enfrentando o processo educacional com alegria e determinação.

Sofia é pedagoga e professora do Ensino Fundamental I há cinco anos e Talita é professora de Matemática do Ensino Fundamental I e II há vinte e sete anos. Ambas trabalhavam em salas especiais, nas quais todos os alunos pertenciam ao público-alvo da Educação Especial no ano em que foi realizada a entrevista. Renata é pedagoga e professora há dez anos e trabalha em uma classe regular inclusiva de $3^{\circ}$ ano do Ensino Fundamental I. Marisa é pedagoga em classe regular do Ensino Fundamental I (anos iniciais) e também faz atendimento hospitalar há catorze anos.

Andrade, Anjos e Pereira (2009) conduziram uma pesquisa na qual se analisa as falas de professores do município de Marabá, coletadas em entrevistas não estruturadas. Semelhante ao apresentado aqui, os autores fazem a análise de discurso dos professores, considerando aspectos relacionados ao sentido que esses atribuem à inclusão. Nesse estudo, a concepção de inclusão dos professores aparece de duas formas: como processo e como produto. Como processo, a inclusão implica tentativas, erros e acertos de todas as pessoas envolvidas (fruto da ação humana); ao ser definida como produto acabado (coisa dada), cabe às pessoas aceitá-la ou não (ANDRADE; ANJOS; PEREIRA, 2009). Cabe destacar que, na primeira situação, pressupõe-se a possibilidade de intervenção, ou seja, de mudar o estado das coisas, o que não é possível na segunda forma.

Acreditamos que o conceito de inclusão é construído a cada dia, em cada escola e por cada uma das pessoas que atuam nas comunidades educacionais. Ouvir as vozes das professoras, que participam do cotidiano escolar com aprendizes autistas, e compreender os sentidos e significados que elas atribuem ao processo de inclusão dessas crianças talvez possa inspirar educadores de todas as áreas.

Nesta pesquisa, as entrevistas foram compostas pelas seguintes perguntas:

i. O que você pensa a respeito da inclusão do aluno autista?

ii. Quais práticas inclusivas você realiza em suas aulas?

iii. Quais atividades/disciplinas mais favorecem o aluno autista?

Nossa proposta consistiu em, a partir das transcrições das entrevistas e por meio da análise de discurso, como proposto por Gee (2001), analisar as crenças epistemológicas e as ações pedagógicas desencadeadas por essas crenças nas salas de aula de professoras que fazem a inclusão de alunos com TEA.

\section{Uma teoria e um método}

A abordagem proposta por Gee (2001, p. 5, tradução nossa) para a análise de discurso é, nas palavras do autor, um método de pesquisa e uma "[...] teoria sobre a natureza da linguagem ${ }^{1}$ em uso". De acordo com ele, construímos e reconstruímos

'Optamos por traduzir o termo language por linguagem por entendermos que os discursos (objetos de análise neste artigo) podem incluir diversas expressões linguísticas como a verbal, corporal, gestual e outras. 
nossos mundos não somente por meio da linguagem, mas ao associá-la a "[...] ações, interações, sistemas de símbolos não linguísticos, objetos, ferramentas, tecnologias e maneiras distintas de pensar, valorizar, sentir e acreditar" (GEE, 2001, p. 11, tradução nossa).

Neste artigo, a partir das falas de quatro professoras que vivenciam o trabalho com alunos autistas, buscamos compreender, por meio da análise de discurso, como proposto por Gee (2001), o sentido/significado que elas atribuem à inclusão e analisar suas crenças epistemológicas e as ações pedagógicas que realizam para promover a inclusão dos seus 'alunos especiais'.

A perspectiva teórica proposta por Gee (2001) envolve, entre outros, dois construtos: os "discursos grandes" (Discurso) e os "discursos pequenos" (discurso). Para ele, Discursos são:

[...] diferentes maneiras em que nós humanos integramos linguagem com "coisas não linguísticas", tais como diferentes maneiras de pensar, agir, interagir, valorizar, sentir, acreditar e usar símbolos, ferramentas e objetos nos lugares certos e nos momentos certos, para representar e reconhecer diferentes identidades e atividades, dar ao mundo material significados certos, distribuir bens sociais da maneira certa, fazer determinados tipos de conexões significativas em nossa experiência e privilegiar certos sistemas de símbolos e formas de conhecer os outros (ou seja, realizar todas as tarefas de construção acima) (GEE, 2001, p. 13, tradução nossa).

Para o termo discurso, Gee (2001) reservou o termo "linguagem em uso", que associaremos a modelos de ação ou à operacionalização para certo Discurso, no nosso caso, a inclusão, ou seja, "[...] quando o discurso é fundido integralmente com 'coisas' não linguísticas para estabelecer identidades e atividades específicas, temos então Discurso" (GEE, 2001, p. 7, tradução nossa).

Conforme mencionamos, cada uma das professoras respondeu às seguintes questões: (i) o que você pensa a respeito da inclusão do aluno autista?; (ii) quais práticas inclusivas você realiza em suas aulas?; (iii) quais atividades/disciplinas mais favorecem o aluno autista? As professoras receberam as questões impressas em papel e, antes de gravarem suas respostas, responderam a algumas perguntas relacionadas à sua trajetória profissional. Durante essa conversa preliminar, elas tiveram conhecimento que se tratava de uma pesquisa relacionada à Educação Matemática e que tínhamos interesse especial em temas associados a essa área. Nossa expectativa era de que as professoras direcionassem suas respostas às suas práticas matemáticas, o que, de modo geral, aconteceu.

Seguindo a proposta de Gee (2001), elaboramos e utilizamos as questões respondidas pelas professoras para adequar o método de análise ao nosso propósito de pesquisa. O ponto central para a análise foi definir como caracterizar o Discurso. Voltando ao texto de Gee (2001, p. 12), verificamos que ele associa Discurso à "linguagem em ação" e a define como um processo de edificação ativa de construir ou reconstruir a "realidade", engajando-se, identificando-se, conectando-se à sua história e à sua cultura, e assumindo uma postura política. Para discursos, Gee (2001) associa a expressão "linguagem em uso"; assim, para caracterizá-los, observamos, nas transcrições das entrevistas, proposições baseadas no significado e no sentido dos Discursos de inclusão. 
O primeiro passo foi estabelecer como apresentaríamos nossos resultados. Como feito por Andrade, Anjos e Pereira (2009), dividimos as falas analisadas em dois Discursos - Discurso de inclusão como processo (DIP) e Discurso de inclusão como produto (DIPR) - que, por sua vez, são constituídos por discursos (d1 e d2) que ora estão centrados nos significados atribuídos à inclusão (d1) ora relacionam-se ao seu sentido (d2), categorizados como apresentamos no quadro 1.

Quadro 1 - Categorização empregada para análise dos discursos

\begin{tabular}{|c|c|c|}
\hline Categoria & $d_{1}$ (significado) & $\mathrm{d}_{2}$ (sentido) \\
\hline \multirow{3}{*}{ DIP } & Discurso da formação adequada & Discurso de inclusão em relação à exclusão \\
\hline & Discurso da adequação do ambiente/material & Discurso de valorização da diversidade \\
\hline & $\begin{array}{l}\text { Discurso de incluir ou excluir alunos pertencentes ao } \\
\text { público-alvo da Educação Especial. }\end{array}$ & Discurso de identificação das habilidades \\
\hline \multirow{4}{*}{ DIPR } & Discurso do direito à Educação e vida social & Discurso de intervenções de ensino \\
\hline & Discurso de inclusão em relação à exclusão & $\begin{array}{l}\text { Discurso voltado ao ensino para maximizar oportunidades } \\
\text { para todos }\end{array}$ \\
\hline & \multirow[t]{2}{*}{ Discurso do cumprimento da lei } & Discurso de adequação do material \\
\hline & & Discurso voltado ao ensino para valorizar a diversidade \\
\hline
\end{tabular}

Fonte: elaborado pelas autoras.

Nas transcrições, inicialmente, grifamos com cores distintas os Discursos de inclusão como processo (DIP) e os Discursos de inclusão como produto (DIPR) e, em uma segunda etapa, elaboramos as categorias dos discursos $\left(d_{1}\right.$ e $\left.d_{2}\right)$. Os $d_{1}$ são caracterizados por falas que sugerem padrões já estabelecidos socialmente (significados), já os $d_{2}$ indicam vozes que manifestam ações que devem ser realizadas pelos envolvidos (sentidos). Em uma análise preliminar, pode-se perceber que, com a experiência, o professor assume a responsabilidade e o domínio de suas ações pedagógicas inclusivas.

\section{As professoras e suas vozes}

Cada uma das questões respondidas pelas professoras nos permitiu analisar um aspecto relacionado ao sentido e ao significado que elas atribuem ao processo de inclusão de alunos autistas, conduzido na instituição na qual trabalham.

\section{A inclusão do aluno autista}

Analisar os discursos das professoras em relação à questão: $O$ que você pensa a respeito da Inclusão do aluno autista? nos possibilita compreender o processo e as possibilidades de inclusão no ambiente escolar. As entrevistas realizadas possibilitaram diferentes discursos, no entanto, é possível perceber um aspecto comum nos dizeres das professoras, relacionado à necessidade de estrutura adequada do ambiente e do meio social no qual o aluno será inserido, características fundamentais para que o aprendiz, pertencente ao público-alvo da educação especial, tenha melhor aproveitamento no cenário educacional. 
As quatro professoras apresentaram Discursos que abordaram os aspectos legais, sociais, a necessidade de intervenções de ensino e a importância da inserção de todos os envolvidos no processo de inclusão; o que categorizamos como DIPR, com discursos $d_{1}$ (relacionados ao sentido) e $d_{2}$ (relacionados ao significado), uma vez que as entrevistadas assumiram posicionamentos políticos em prol do direito à educação de pessoas pertencentes ao público-alvo da Educação Especial e mostraram a ideia de inclusão alicerçada nas intervenções de ensino. É o que os trechos das entrevistas que seguem destacam:

Todos têm direito a Educação... tanto a estrutura da escola, como os profissionais. [Renata].

[...] é uma nova fase que estamos se adaptando com as novas políticas e os professores têm que se adequar com esse novo formato. É adaptando o currículo, é fazendo, é desenvolvendo a comunicação, desenvolvendo as habilidades de muitos deles né? Tanto os que têm maior ou menor dificuldade. [Marisa].

[...] compartilharem do mesmo ambiente social ... Tanto na parte pedagógica como social. Hoje, independente da inclusão ser uma lei, eu acho que ela tem que ser sim exercida. [Talita].

Inclusão? Tanto no meio social... o ambiente. Então, só ter o aluno na sala de aula regular, só ter um aluno autista na sala de aula regular, eu acredito que não seja inclusão, né? Eu acredito que seja cumprir o currículo, né? Cumprir com aquilo que estão mandando, então isso não é inclusão. [Sofia].

De fato, as professoras reconhecem que a Educação é um direito de todos e que a inclusão, apesar de ser lei, é mais do que compartilhar o mesmo espaço físico. A interação com crianças de mesma faixa etária permite que os alunos com TEA vivenciem experiências de troca de ideias e de papéis, de negociação e discussão para a solução de conflitos. Nas atividades entre pares, criam-se regras para a competição e colaboração (BOSA; CAMARGO, 2009). Ao oferecer a todos a oportunidade de participar ativamente das práticas escolares, o professor valoriza a diversidade e pode identificar habilidades dos seus alunos. Ainscow (1999) argumenta que as escolas precisam de técnicas pedagógicas que possam responder positivamente à diversidade dos alunos, isto é, abordando as diferenças individuais não como problemas a serem consertados, mas como oportunidades para enriquecer o aprendizado.

Nas transcrições, identificamos também aspectos relacionados ao Discurso da inclusão enquanto processo (DIP), constituído de discursos $\left(d_{1}\right.$ e $\left.d_{2}\right)$, nas vozes das professoras ao responderem a primeira questão; isso indica a preocupação com a formação profissional adequada e as ações pedagógicas realizadas no processo de inclusão dos alunos pertencentes ao público-alvo da Educação Especial no ambiente escolar, ou seja, Discursos constituídos por reflexões sobre as ações inclusivas, promovidas no ambiente escolar, como os seguintes:

Todos os que estão envolvidos, precisam, precisam estar preparados. [Renata].

Inclusão é pensar nele [o aluno pertencente ao público-alvo da Educação Especial] e num todo, a turma num todo, porque a gente também não pode também pensar só no autista. A gente também tem que pensar nos outros alunos, como que eles vão receber isso, como eles vão lidar com isso? Existem momentos em que a gente faz inclusão com as turmas regulares. Algumas atividades, por exemplo, educação física e artes, eles fazem juntos. Tem que ser muito pensada [a inclusão]. Hoje em dia existe um déficit muito grande de profissionais que querem colocar a mão na massa, né? As especializações 
existem com muito custo... né? São poucas, é um mercado escasso, não é? São poucas as pessoas que têm acesso as informações realmente verdadeiras, realmente necessárias, né? Existe muita gente que recebe esses alunos autistas, mas não sabe como lidar e acaba excluindo...? [Sofia].

Os Discursos revelam aspectos críticos das falas das professoras. Como apontado por pesquisadores que discutem o ensino para o público-alvo da Educação Especial - como Fernandes e Healy (2006), por exemplo -, de modo geral, as professoras se ressentem de formação adequada, seja ela inicial ou continuada, para trabalhar com o público-alvo da Educação Especial. Como destacam Pletsch e Lima (2014), o incentivo à formação e à capacitação de profissionais para o atendimento aos alunos com TEA e o apoio aos pais e responsáveis, colocando-os em situação de parceria com a escola, são ações fundamentais para a educação de qualidade de todos aqueles com necessidades educacionais especiais. Isso nos leva ao desafio de preparar os professores para trabalhar com todos os alunos, incluindo aqueles que anteriormente estavam em escolas especializadas; um processo que requer a ressignificação de suas crenças pedagógicas e epistemológicas.

\section{Práticas inclusivas}

A presença de alunos pertencentes ao público-alvo da Educação Especial, nas instituições de ensino, traz à escola desafios no sentido de adequar-se, cada vez mais, para responder às demandas educacionais, que são ainda mais peculiares, no caso de aprendizes com TEA. Ainscow (2016) sugere que as escolas podem apoiarse na necessidade de responder à diversidade de seus alunos para estruturar seu desenvolvimento e sua capacidade de trabalho.

Subjacente às nossas propostas está a crença de que as diferenças podem
atuar como um catalisador para a inovação de maneiras que têm o potencial
de beneficiar todos os alunos, quaisquer que sejam as suas características
pessoais e circunstâncias domésticas (AINSCOW, 2016, p. 148, tradução nossa).

O professor, por sua vez, depara-se, constantemente, com a necessidade de lançar mão de diferentes práticas de ensino para propiciar condições de aprendizagem, na sala de aula, que não excluam nenhum aluno. Ainda de acordo com Ainscow (2016), toda escola se fortalece em sua capacidade de atender à diversidade se desenvolver, de forma colaborativa e compartilhada, boas práticas inclusivas. Infelizmente, não é comum vivenciarmos momentos de discussões sobre experiências bem-sucedidas em salas de aula. Na maioria dos casos, as ações são individuais e relacionam-se ao fazer pedagógico do professor, como relatam Andrade, Anjos e Pereira (2009).

A seguir, compartilhamos trechos das entrevistas das professoras relacionadas às práticas que adotam na sala de aula, ao responderem à questão Quais práticas inclusivas você realiza em suas aulas?

A professora Marisa destacou, em sua resposta, que "As práticas inclusivas realizadas em salas, é adaptar sempre os materiais, na perspectiva de que o aluno consegue ou gosta de fazer". Na análise das audições e das transcrições, verificamos que a professora não se coloca como primeira pessoa no discurso, ou seja, como agente da ação que propõe, o que nos levou a categorizá-lo como DIPR/d 2 . Para ela, a adaptação 
de materiais é ponto passivo, mas, para fazê-lo, procura atender os gostos e respeitar a capacidade do aluno. Os discursos das três outras professoras foram categorizados como DIP/d .

[...] Adaptação de material. Adaptação de dinâmica, pra que todo mundo participe da aula e respeitando as limitações de cada um, que eu acho que isso é muito importante! [Renata].

[...] procuro trazer vídeos que expliquem..., imagens pra que eles consigam fazer a comparação, pra que eles assimilem ... Tudo com cores, tudo que seja concreto, pra que, essa atividade, essas aulas sejam mais significativas. Nós trazemos para o concreto, e se for possível fazemos a confecção de materiais. Então eles precisam que tenha algo concreto, algo que eles possam ver ou tocar. Né? Acho que pra eles é mais significativo. Mais interessante dessa forma! [Sofia].

[...] eles também têm aulas com especialistas, exemplo, na aula de artes, eles têm um professor, que costuma dar muita coisa de pintura e artesanato. Na aula de música, nós temos instrumentos musicais, temos também um estúdio, aonde eles também possam explorar essa parte deles de instrumentos musicais de canto. Nós também temos a educação física, onde também é explorado bastante atividades físicas. Aula de ciências, aonde é dado no laboratório. Geografia, história. Enfim... são todas as disciplinas do currículo normal... [Talita].

A professora Renata relata ações e destaca a importância da participação de todos e o respeito às limitações de cada um. Ambos os outros dois Discursos, das professoras Sofia e Talita, a presentam práticas pedagógicas nas quais as representações dos objetos são multissensoriais e as habilidades dos educandos são exploradas por meio de diferentes interações.

A abordagem de ensino multissensorial contempla a oportunidade de acesso ao conhecimento por meio de diferentes canais sensoriais, ou seja, o processo de aprendizagem pode ser explorado via tato, olfato, visão, audição, movimentos do corpo. No caso de nossas pesquisas, a relação com os objetos matemáticos só é possível por meio de suas representações e, neste sentido, a aprendizagem matemática deve envolver ações perceptivas sobre uma variedade de representações do objeto matemático em estudo (HEALY; FERNANDES, 2011).

Incluir crianças com autismo vai além de colocá-las em salas regulares, é preciso oferecer a elas aprendizagens significativas, capazes de desenvolver suas potencialidades, "[...] constituindo, assim, o sujeito como um ser que aprende, pensa, sente, participa de um grupo social e se desenvolve com ele e a partir dele, com toda sua singularidade" (PLETSCH; LIMA, 2014, p. 6).

\section{Práticas utilizadas nas aulas de Matemática com aprendizes autistas}

A diversidade e a personalização são elementos fundamentais que devem ser observados no sistema educacional para que ocorra a educação e a inclusão de alunos com autismo (FLEIRA, 2016). Observando, em particular, o ensino da matemática escolar que segue o modelo tradicional (giz, lousa, aulas expositivas) e oferece padrões didáticos convencionais, percebe-se que este não consegue suprir as necessidades dos alunos com TEA ou mesmo daqueles com desenvolvimento típico. 
Os Discursos (DIP) envolvendo as práticas nas aulas de Matemática, proferidos pelas professoras, apresentaram discursos $\left(d_{1}\right.$ e $\left.d_{2}\right)$ com reflexões e ações que envolveram a adequação do material, do ambiente, a valorização da diversidade e a identificação das habilidades.

A matemática é que trabalha o raciocínio lógico, a memória, e a educação financeira. Educação financeira
naquele contexto de que a gente possa fazer atividades de supermercado, de algum ambiente de comércio,
pra gente ir numa papelaria, numa farmácia, numa banca de jornal, pra gente poder trabalhar com esse
conceito de público, de pagar, de receber troco, e eles gostam bastante. [Marisa].

[...] normalmente eu sempre procuro identificar quais os pontos mais relevantes de cada aluno, quais os pontos que chamam mais atenção, e elaborar atividades que envolvem os assuntos que eles mais se interessam, assim favorece muito a interação, o interesse deles na atividade, o empenho em realizar. Acredito que é isso! [Renata].

Ao analisarmos os Discursos das educadoras Marisa e Renata, percebemos Discursos $\left(D I P / d_{1}\right)$ atribuídos à inclusão nas aulas de matemática. Ambas apresentam uma fala frequente em modelos pedagógicos, marcados por expressões usuais, como: educação financeira, raciocínio lógico, identificar pontos relevantes e outros. As professoras associam suas ações à adequação do ambiente e do material.

Os Discursos $\left(D I P / d_{2}\right)$ de Sofia e Talita estão repletos de reflexões sobre as ações, em busca de sentido tanto para os aprendizes pertencentes ao público-alvo da Educação Especial envolvidos, quanto para as educadoras. Vejamos alguns trechos das entrevistas que ilustram nossas ideias:

[...] trabalhado no lúdico, trabalhado em forma de brincadeira, é mais concreto, é mais significativo... não só alunos autistas, mas como toda e qualquer criança. [Sofia].

Por exemplo: Nós vamos fazer uma culinária. [...] nós precisamos dos ingredientes, então primeiro eu administro àquilo que nós vamos fazer, o que vai ser preciso pra nossa culinária e daí nós vamos a pé ao supermercado... E lá, eu acabo aproveitando pra trabalhar a matemática, né? Devido a quantidade dos ingredientes, e também a parte deles... financeira..., quanto vão gastar, a parte do troco... E após isso, chegando, eu também aproveito na hora de fazermos a culinária... eu acabo utilizando, no lugar de xícaras, colheres... porquê?... exploro os números, a quantidade, os ingredientes, dinheiro. E também, a partir do momento que estamos fazendo a culinária, existe também a utilização do que for necessário, por exemplo, um forno elétrico, um micro-ondas e quando finalizamos a culinária, nós também costumamos ter que lavar a culinária, tudo que nós usamos. Então isso também faz com que eles entram vida prática, onde eles vão ter que lavar tudo aquilo que eles sujaram, né? E isso também auxilia na independência da vida deles como adultos. [Talita].

Ao analisarmos os Discursos das entrevistadas nas aulas de Matemática, percebemos que, mesmo em diferentes graus, todas mostraram ter expectativas em relação à aprendizagem dos alunos, valorizar as produções dos aprendizes e acreditar no potencial de todos, indiferentemente da especificidade de cada um.

Ao adotar a abordagem correta, podemos criar um novo mundo para nossas crianças deficientes. [...] a introdução de uma educação social que incentivasse as crianças deficientes a se tornarem trabalhadores socialmente valorizados eliminaria a ideia de defeito como um fato social na nova sociedade. (VEER; VALSINER, 2001, p. 78). 
Analisando os Discursos das professoras, sob a perspectiva da Educação Inclusiva, acreditamos que o olhar especial, focado nas habilidades e peculiaridades de cada indivíduo, pode promover a interação social e o melhor rendimento na aprendizagem de todos os envolvidos por meio da mediação do professor e de diferentes práticas pedagógicas.

\section{Considerações finais}

Ao darmos voz às quatro professoras e analisarmos os Discursos das entrevistadas, percebemos que todas acreditam no potencial para aprender de todos os alunos e têm experiências exitosas relacionadas à inclusão de alunos com TEA. Em alguma medida, o Discurso das professoras revela uma faceta da inclusão vista como um produto (DIPR) social ou mesmo político, mas isso não as impede de assumir uma postura de enfrentamento dos desafios associados à sua implementação.

As professoras revelam estar conscientes de seu papel e de suas responsabilidades frente à educação de todos os seus alunos e mostram ter conhecimentos sobre o tema Inclusão de alunos com TEA por demonstrarem um amplo repertório de práticas pedagógicas que são empregadas nas aulas de Matemática. No entanto, percebemos que os Discursos diferem em duas vertentes. Notamos que grande parte dos discursos de Marta e Renata foi categorizada como DIPR com discursos $\left(d_{1}\right.$ e $\left.d_{2}\right)$, ou seja, Discursos nos quais a inclusão é Produto - ações pedagógicas propostas e amparadas por leis. Ambas as professoras trabalham para incluir seus alunos da maneira que acreditam ser a melhor. Em nossas interpretações, as ações delas pareceram estar mais associadas a um significado para a inclusão, ou seja, são práticas oriundas de deveres, sem que estejam necessariamente ligadas à práxis reflexiva. Já Sofia e Talita apresentaram Discursos DIPR e DIP, com discursos $\left(d_{1}\right.$ e $\left.d_{2}\right)$, que, ao analisarmos, notamos que suas práticas pedagógicas, desenvolvidas em sala, foram fruto de reflexões na perspectiva de aprimorar e fazer melhor do que o proposto pelo sistema educacional. As falas dessas professoras registram suas crenças na capacidade de aprender dos seus alunos e respeitam suas formas de expressão.

Por exemplo, nas aulas de matemática, se eu vou trabalhar com números, identificação de números, eu vou usar um dado, vou fazer a quantificação, "quantas bolas têm? cinco! Qual que é o número cinco lá no dado? Entendeu? Então a gente vai fazendo por meio de brincadeira e só depois que eles conseguiram associar as atividades de forma lúdica e concreta é que a gente passa a escrever, né? Aqueles alunos que conseguem escrever, eles vão começar a escrever. Como que escreve o número cinco e... existem aqueles alunos autistas que não têm coordenação motora fina capaz de escrever, [...], mas eles conseguem falar, então, fale, vamos falar qual que é o número cinco, vamos apontar, para aquele aluno que não consegue falar, vamos apontar. Pegue e coloque, coloque ali, coloque aqui. Então tudo pra eles tem que ser muito concreto e sempre adaptado. Então dá pra fazer uma atividade adaptada que seja concreta, significativa pra todos os alunos, independente do nível, porque todo aluno chama atenção, né? Chama a atenção e é interessante em forma de brincadeira, todo aluno gosta de brincar, e não é diferente pros autistas. 
- A inclusão é um processo. [...]. Trata-se de aprender a viver com a diferença, e, aprender a aprender com a diferença [...].

- A inclusão preocupa-se com a identificação e remoção de barreiras. [...]. Tratase de usar evidências de vários tipos para estimular a criatividade e a resolução de problemas.

- Inclusão é sobre a presença, participação e realização de todos os alunos [...].

- A inclusão envolve ênfase particular nos grupos de alunos que podem estar em risco de marginalização, exclusão ou falta de desempenho [...] (AINSCOW, 2016, p. 147, tradução nossa).

Consideramos que as escolas inclusivas são aquelas que percebem a diversidade como um fator de enriquecimento do ser humano e do processo educacional. Apesar das leis, das ações e dos movimentos sociais, estamos todos aprendendo a lidar com a diversidade que, de repente, 'revelou-se', e reconhecer que a configuração da sala de aula atual não é a idealizada pela literatura e pelos documentos é um primeiro passo. Acreditamos que este artigo poderá colaborar com os professores que atuam na educação inclusiva, com alunos autistas e esperamos que os discursos inspirem reflexões acerca das práticas pedagógicas desses educadores.

\section{Referências}

AINSCOW, M. Diversity and equity: a global education challenge. New Zealand Journal of Educational Studies, New Zealand, v. 51, p. 143-155, 2016. DOI: https://doi.org/g2cc.

AINSCOW, M. Tornar a escola inclusiva: como essa tarefa deve ser conceituada? In: FÁVERO, O.; FERREIRA, W.; IRELAND, T.; BARREIROS, F. (org.). Tornar a educação inclusiva. Brasília: UNESCO, 2009. p. 11-23.

AINSCOW, M. Understanding the development of inclusive schools. London: Falmer, 1999.

AMERICAN PSYCHIATRIC ASSOCIATION. Manual diagnóstico e estatístico de transtornos mentais: DSM-5. 5. ed. Porto Alegre: Artmed, 2014.

ANDRADE, E. P.; ANJOS, H. P.; PEREIRA, M. R. A inclusão escolar do ponto de vista dos professores: o processo de constituição de um discurso. Revista Brasileira de Educação, Rio de Janeiro, v. 14, n. 40, p. 116-129. DOI: https://doi.org/dpktb8.

BASTOS, R. P. Ações, relações e sentidos produzidos pela comunidade escolar sobre o processo de inclusão da criança com TEA. 2019. Dissertação (Mestrado em Psicologia) - Universidade Federal do Amazonas, Manaus, 2019. Disponível em: https://tede.ufam.edu.br/handle/tede/7062. Acesso em: 3 dez. 2019.

BOSA, C. A.; CAMARGO, S. P. H. Competência social, inclusão escolar e autismo: revisão crítica da literatura. Psicologia \& Sociedade, Recife, v. 21, n. 1, p. 65-74, 2009. DOI: https://doi.org/d65bb5.

COSENZA, R. M.; GUERRA, L. B. Neurociência e educação: como o cérebro aprende. Porto Alegre: Artmed, 2011.

DAMÁSIO, A. O mistério da consciência: do corpo e das emoções ao conhecimento de si. 7. ed. São Paulo: Companhia das Letras, 2005.

FERNANDES, S. H. A. A. Educação matemática inclusiva: adaptação x construção. Revista Educação Inclusiva, Campina Grande, v. 1, n. 1, p. 78-95, 2017. Disponível em: https://revista.uepb.edu.br/ REIN/article/view/68. Acesso em: 3 de maio 2019.

FERNANDES, S. H. A. A.; HEALY, L. O processo de inclusão de alunos cegos nas aulas de matemática: as vozes dos atores. In: SEMINÁRIO INTERNACIONAL DE PESQUISA EM EDUCAÇÃO MATEMÁTICA, 3., 2006, Águas de Lindóia. Anais [...]. São Paulo: SBEM, 2006. v. 1. 
FLEIRA, R. C. Intervenções pedagógicas para a inclusão de um aluno autista nas aulas de matemática: um olhar vygotskyano. 2016. Dissertação (Mestrado em Educação Matemática) Universidade Anhanguera de São Paulo, São Paulo, 2016. Disponível em: https://repositorio. pgsskroton.com//handle/123456789/21815. Acesso em: 12 out. 2021.

GALLESE, V. Embodied simulation: from neurons to phenomenal experience. Phenomenology and the Cognitive Sciences, Dordrecht, v. 4, p. 23-48, 2005. DOI: https://doi.org/cmgf9r.

GEE, J. An introduction to discourse analysis: theory and methods. New York: Routledge, 2001.

GIL, A. C. Métodos e técnicas de pesquisa social. 5. ed. São Paulo: Atlas, 1999.

HEALY, L.; FERNANDES, S. H. A. A. The role of gestures in the mathematical practices of those who do not see with their eyes. Educational Studies in Mathematics, Dordrecht, v. 77, p. 157-174, 2011. DOI: https://doi.org/b4wbhg.

LUDKE, M.; ANDRÉ, M. E. D. Pesquisa em educação: abordagens qualitativas. São Paulo: Editora Pedagógica e Universitária, 1986.

PLETSCH, M. D.; LIMA, M. F. C. A inclusão escolar de alunos com autismo: um olhar sobre a mediação pedagógica. In: SEMINÁRIO INTERNACIONAL DE INCLUSÃO ESCOLAR, 1., 2014, Rio de Janeiro. Anais [...].Rio de Janeiro: Universidade do Rio de Janeiro, 2014. p. 1-10. Disponível em: http://www.cap.uerj.br/site/images/stories/noticias/4-Pletsch_e_Lima.pdf. Acesso em: 5 maio 2019.

VEER, R. V.; VALSINER, J. Vygotsky: uma síntese. 4. ed. São Paulo: Loyola, 2001.

VYGOTSKY, L. A construção do pensamento e da linguagem. 2. ed. São Paulo: WMF Martins Fontes, 2009. 